
July 1938

\title{
PREPARATION AND APPLICATION OF CHROMOUS SOLUTIONS FOR THE ABSORPTION OF OXYGEN IN VOLUMETRIC GAS ANALYSIS
}

\author{
By Joseph R. Branham
}

\section{ABSTRACT}

The reaction between acidified and nonacidified solutions of chromous chloride or of chromous sulfate with oxygen was studied and found to be complete $( \pm 0.02$ percent). Acidified solutions of chromous sulfate evolve hydrogen sulfide and should not be used for volumetric analysis over mercury. Acidified solutions of chromous chloride evolve small amounts of hydrogen. The errors caused by this hydrogen are of the same order of magnitude as those caused by the formation of carbon monoxide when oxygen is determined by absorption in alkaline potassium pyrogallate. The displacement of dissolved nitrogen from the chromous solutions, particularly chromous sulfate, and the subsequent partial re-solution of this nitrogen may cause low apparent percentages of oxygen in the samples to be reported. Alkaline potassium pyrogallate and concentrated acidified solutions of chromous chloride should be used to determine oxygen volumetrically, in preferenee to the more dilute solutions of chromous sulfate prepared by reduction of saturated solutions of potassium chromic sulfate.

\section{CONTENTS}

Page

I. Introduction

II. Preparation of solutions

III. Evolution of hydrogen sulfide from chromous solutions._.

IV. Apparatus and procedure _.

V. Completeness of the reaction between oxygen and chromous solutions_ 49

VI. Evolution of hydrogen from chromous solutions and of carbon monoxide from alkaline potassium pyrogallate.

VII. Displacement of nitrogen from chromous solutions during analyses_... 52

VIII. Results of analyses of mixtures of oxygen and nitrogen_._.

IX. Conclusion.

\section{INTRODUCTION}

Many chemists have suggested that the reaction between oxygen and solutions which contain either chromous chloride or chromous sulfate be used to determine the oxygen content of gas mixtures by the methods of volumetric gas analysis. ${ }^{1}$

The advantages claimed for these solutions are great speed of reaction and the selective chemical absorption of oxygen from gas mixtures which contain carbon dioxide.

1 Otto von der Pfortden first proposed the use of chromous chloride for this purpose. Liebigs Ann. Chem. 228, 112 (1885). Anderson and Riffe examined the reaction between acidified and nonacidified solutions of chromous chloride and oxygen and reported that the first of these reagents evolved too much hydrogen to be used in volumetric gas analysis, while the second did not absorb all of the oxygen in the gas samples. J. Ind. Eng. Chem. 8, 24 (1916). Hosmer W. Stone and Charles R. Dixon, at the Rochester meeting of the American Chemical Society in September 1937, suggested that acidified and nonacidified solutions of chromous sulfate might be used to determine oxygen volumetrically. 
When the oxygen in mixtures of gas containing oxygen and nitrogen is determined volumetrically, it is customary, and for exact work necessary, to absorb the oxygen in a reagent which is saturated with nitrogen at the beginning and end of each analysis. The amount of oxygen reported is the difference between the volumes of gas in the apparatus before and after the sample has been passed through the reagent. The apparent percentage of oxygen in the sample will therefore depend not only on the volume of oxygen which reacts, but also on the volume of nitrogen or any other gas that is absorbed by or displaced from the reagents during the analysis.

For these reasons solutions of chromous sulfate and chromous chloride were examined with reference to: (1) Completeness of the reaction between them and oxygen; (2) formation and subsequent liberation of hydrogen; (3) formation and subsequent liberation of hydrogen sulfide; and (4) physical solution and displacement of nitrogen from these reagents during the chemical absorption of oxygen.

\section{PREPARATION OF SOLUTIONS}

The chromous solutions used in this study were prepared either from violet chromium potassium sulfate or from green chromic chloride by reduction with amalgamated zinc. The solubilities of these two salts are approximately 0.4 and 4.0 moles per liter; and the latter salt was used when concentrated solutions of chromous chloride were prepared. Solutions containing green chromic chloride are not appreciably reduced by amalgamated zinc unless an excess of hydrochloric acid is present. Neutral ${ }^{2}$ solutions of chromous chloride were prepared by adding an excess of barium chloride to solutions of neutral chromous sulphate and filtering off the barium sulphate which precipitated, all operations being performed under an atmosphere of nitrogen.

The solutions of chromous sulfate were prepared from chromium potassium sulfate by reduction with amalgamated zinc in a Jones reductor. Nitrogen was substituted for the carbon dioxide used by Stone and Beeson ${ }^{3}$ to force the solutions through the reductor. It was necessary to reduce the green chromic chloride in an Erlenmeyer flask nearly full of amalgamated mossy zinc, because the Jones reductor containing 20 -mesh zinc was clogged by a precipitate under these conditions. The time required for the reduction of the green chloride in the flask was greater than that for the reduction of the chromium potassium sulfate in the Jones reductor, but required no great amount of attention. Nitrogen was bubbled through the solutions prepared from chromic salts by reduction with amalgamated zinc, in order to free them from dissolved hydrogen and to saturate them with nitrogen (in accordance with normal yolumetric procedure) before they were transferred to the absorption pipettes.

\section{EVOLUTION OF HYDROGEN SULFIDE FROM CHROMOUS SOLUTIONS}

All of the solutions of chromous chloride and of chromous sulfate prepared in the earlier stages of this work evolved hydrogen sulfide. Very low concentrations of this gas react with the mercury in the

${ }^{2}$ This term is used throughout this paper to denote aqueous solutions to which no acid was added.

3Ind. Eng. Chem. Anal. Ed. 8, 188 (1936). 
burette and manometer of a volumetric gas-analysis apparatus, and, by altering the shape of the menisci, prevent accurate volumetric measurements. ${ }^{4}$ The presence of hydrogen sulfide was established by bubbling nitrogen through the solutions and passing the exit gas over paper moistened with lead acetate or over the clean surface of mercury.

There are at least three ways by which the chromous solutions may be contaminated with hydrogen sulfide. These are: (1) From combined sulfide and possibly sulfate as impurities in the zinc used to reduce the chromic salts; (2) from the sulfur compounds as impurities in liquid petrolatum when this is used to prevent contact between the free surface of the chromous solutions and the atmosphere in the open arm of an absorption pipette; and (3) by reduction of the sulfate radical in the presence of sulfuric acid and bivalent chromium.

Samples of mossy, stick, and "20-mesh" zinc from freshly opened containers evolved hydrogen sulfide when treated with dilute hydrochloric acid. The concentration of this gas was greatest during the first acid treatment and diminished when the zinc was washed and fresh portions of acid were added to the flask. Three or more 10minute reactions with fresh acid were necessary before the zinc was sufficiently pure to be amalgamated and used to produce chromous solutions free from hydrogen sulfide. Zinc treated in this way, before being amalgamated by treatment with mercuric chloride, produced neutral solutions of chromous sulfate and acid solutions of chromous chloride which did not evolve detectable amounts of hydrogen sulfide during the period covered by the tests.

The evidence concerning the presence or absence of hydrogen sulfide and also of hydrogen in the neutral solutions of chromous sulfate is not completely satisfactory. Both hydrogen and hydrogen sulfide were displaced from some of the neutral solutions of chromous sulfate when relatively long periods elapsed between their use in analyses. On the basis of the volumes of nitrogen which had been passed through these solutions during the analyses performed prior to the period during which the reagent was idle all of the hydrogen or hydrogen sulfide in the reagent by reason of the method of preparation should have been displaced. It appears quite probable therefore that both hydrogen and hydrogen sulfide are generated slowly by this reagent.

When hydrogen sulfide-free solutions of chromous chloride acidified with hydrochloric acid were stored under a layer of liquid petrolatum, to protect them from direct contact with air at their open surface in the atmospheric arm of an absorption pipette, they became contaminated with hydrogen sulfide. The amount of hydrogen sulfide displaced from the solutions under these conditions was small, but sufficient to gradually blacken the mercury in the volumetric apparatus and, in time, to impair the accuracy of the volumetric determinations. Hydrogen sulfide from this source was eliminated by substituting an atmosphere of nitrogen for the layer of liquid petrolatum in the open arm of the absorption pipettes.

The reduction of sulfur compounds in liquid petrolatum to hydrogen sulfide was confirmed in the following manner. An acid solution of chromous chloride was prepared and equal volumes of it were put

\footnotetext{
${ }^{4}$ According to H. A. Bright, of this Bureau, the extremely small amount of hydrogen sulfide which prevents the accurate determination of gas volumes over mercury is of negligible consideration in titrimetric or gravimetric methods employing zinc and acid for reduction.
}

$71531-38-4$ 
into two gas-washing bottles. Liquid petrolatum was added to one of these and a current of nitrogen passed through the two bottles in series. Tests with lead acetate papers showed that the exit gas from the bottle containing the chromous solution in contact with liquid petrolatum contained hydrogen sulfide. This test was negative in the case of the bottle which contained only chromous chloride.

Attempts to prepare acid solutions of chromous sulfate which were free from hydrogen sulfide were unsuccessful. Experimental evidence of the reduction of the sulfate radical to hydrogen sulfide by bivalent chromium in the presence of sulfuric acid was obtained as follows:

1. The absence of hydrogen sulfide in a solution of chromous chloride, containing hydrochloric acid, was established by passing nitrogen through it and then over lead acetate paper. No lead sulfide was formed. This test was then repeated after the addition of sulfuric acid to the chromous solution. The paper darkened almost immediately.

2. One-fourth of a single sample of a neutral chromous sulfate solution was put into each of four gas-washing bottles, three of which contained measured volumes of sulfuric acid. These bottles were connected in series, the first being neutral, while the second, third, and fourth contained sufficient sulfuric acid to make them $0.1,1.0$, and $5 \mathrm{~N}$. Lead acetate papers were put in the exit connection of each bottle and nitrogen was passed through them. The lead acetate paper placed in the exit gas from the neutral solution showed only a trace of color after a long exposure, but the papers exposed to the gas which had passed through the acid solutions darkened in a few minutes.

\section{APPARATUS AND PROCEDURE}

Volumetric measurements were made over mercury in the gasanalysis apparatus previously described. ${ }^{5}$ The calibration of the burette permitted volumes to be estimated to $0.01 \mathrm{ml}$ and readings by independent observers rarely differed more than $0.02 \mathrm{ml}$. This does not necessarily mean that gas volumes were determined accurately within $\pm 0.02 \mathrm{ml}$, but rather that the apparent volume of the gas, which may or may not have been the correct volume, was repeatedly observed within these limits. This apparatus is equipped with a mercury-filled manometer, between the burette and compensator, one side of which is in contact with the gas being measured The reaction between oxygen and the chromous solutions took place in one of two Schott \& Genossen pipettes. ${ }^{6}$ These were equipped with distributor tips of sintered glass of porosity grade G2. The solution in the atmospheric arm of the pipette containing a chromous solution was protected from contact with air by connecting its atmospheric arm with an extra pipette which contained alkaline potassium pyrogallate. The open surface of the chromous solutions was thereby maintained under an atmosphere of nearly pure nitrogen. A layer of liquid petrolatum was used to prevent direct contact between the potassium pyrogallate and the atmosphere.

The volumetric apparatus was also equipped with a slow-combustion pipette and an absorption pipette containing alkaline potassium

$\checkmark$ Martin Shepherd, BS J. Research 6, 121 (1931) RP266.

'These pipettes are listed as 153-SG2 on page 18 of the catalog of the Fish-Schurman Corporation of New York City. 
pyrogallate. ${ }^{7}$ The combustion pipette was used in the determination of the hydrogen evolved by the chromous solutions during the absorption of oxygen. The residual gas after reaction with the chromous solutions was passed through potassium pyrogallate to determine the completeness of the reaction between oxygen and the chromous solutions.

Mixtures of oxygen and nitrogen for analysis were taken from two sources. These were: (1) Air, drawn from outside of the building by means of a copper tube and freed from carbon dioxide by passage through ascarite; and (2) a cylinder of commercial oxygen obtained by rectification of liquid air. ${ }^{\text {. }}$ This oxygen contained no measurable amounts of carbon dioxide or combustible gases.

When commercial oxygen was analyzed, by absorption in the chromous solutions or in potassium pyrogallate, a measured volume of nitrogen (to serve as a carrier gas) was stored in the absorption pipette above the solution before the oxygen in the sample was absorbed. This nitrogen was needed in the latter stages of an absorption to carry the last portions of unabsorbed oxygen through the solutions in the pipettes, and to saturate the reagent with nitrogen at the end of each analysis. The difference between the volume of nitrogen which was stored at the beginning of an analysis and that left at the end of the analysis is the apparent "nitrogen" or inert content of the sample.

\section{COMPLETENESS OF THE REACTION BETWEEN OXYGEN AND CHROMOUS SOLUTIONS}

R. P. Anderson and J. Riffe ${ }^{9}$ investigated the reaction between oxygen and a neutral solution of chromous chloride. They reported that this solution will absorb only about 97 percent of the oxygen in air. They also found that acidified solutions of chromous chloride liberate sufficient hydrogen to make them unsuitable for use in volumetric gas analysis.

The results obtained by Anderson and Riffe were not confirmed in the present study. Repeated tests showed that the gas which remained after air or commercial oxygen had reacted with acid or neutral solutions of either chromous chloride or chromous sulfate underwent no measurable change of volume when passed through potassium pyrogallate. The absence of measurable volumes of oxygen in the gas which remained after oxygen had reacted with acid chromous chloride, which evolved some hydrogen, was also shown by the absence of a contraction when this gas was passed over a heated platinum spiral in the slow-combustion pipette.

\footnotetext{
7 This solution was prepared by adding $15 \mathrm{~g}$ of pyrogallic acid dissolved in $10 \mathrm{ml}$ of hot water to each 100 ml of a solution which was saturated with potassium hydroxide at room temperature. There is a possibility that some of the hydroxide solutions used were not completely saturated because of lack of stirring, even though there was an excess of the solid present. This may account in part for the relatively large amriunts of carbon monoxide found in the gas which remained after oxygen (approximately 99 percent) was absorbed by severa! batches of alkaline potassium pyrogallate. For the preparation and use of this reagent see: R. P. Anderson, J. Ind. Eng. Chem. 7, 587 (1915).

${ }^{8}$ This oxygen was of higher purity than is usual, owing to especial precautions taken by the Southern Oxygen Company of Washington, D. C., in the operation of the air rectifier and in filling the cylinder.

8 J. Ind. Eng. Chem. 8, 24 (1916). The chromous chloride used by these investigators was prepared by reducing violet chromic chloride in a current of hydrogen at 400 to $500^{\circ} \mathrm{C}$. The reduced salt was dissolved in water and used to absorb oxygen. The completeness of the reaction between oxygen and this solution was measured by shaking air and chromous chloride together in a contact pipette and then treating the residual gas with potassium pyrogallate. The treatment of the residual gas with potassium pyrogallate increased the apparent oxygen content of air from about 20.3 to 20.95 percent. These investigators did not definitely identify the gas absorbed by potassium pyrogallate as oxygen, and there is a possibility that the reaction between oxygen and the chromous solution was complete but was accompanied by the liberation of carbon dioxide or some other acid gas from the solution. (See RP 1113. Displacement of nitrogen from and its solution in certain reagents. J. R. Branham and Max Sucher.)
} 


\section{EVOLUTION OF HYDROGEN FROM CHROMOUS SOLUTIONS AND OF CARBON MONOXIDE FROM ALKALINE POTASSIUM PYROGALLATE}

The hydrogen or carbon monoxide evolved from the reagents during analyses was determined by slow combustion in the presence of an excess of oxygen. The hydrogen was calculated from the contraction and the oxygen consumed; and the carbon monoxide from contraction, oxygen consumed, and carbon dioxide formed. Carbon monoxide was also determined in one instance by reaction with iodine pentoxide. ${ }^{10}$ The error introduced into the apparent percentages of oxygen by the evolution of hydrogen is of the same order of magnitude as the similar error introduced by the formation of carbon monoxide during the determination of oxygen by absorption in alkaline potassium pyrogallate. It is probable, however, that the amount of hydrogen displaced from the acidified solutions of chromous chloride will increase if the solution stands idle for long periods. This will cause serious errors unless the dissolved hydrogen is swept out of the reagent by nitrogen before it is used to determine oxygen. This sweeping out is not necessary with alkaline potassium pyrogallate because the carbon monoxide displaced from this reagent is supposedly formed only during the absorption of oxygen.

The amounts of hydrogen or of carbon monoxide evolved by the reagents during the analysis of a single $80-\mathrm{ml}$ sample of commercial oxygen were too small to be determined precisely by slow combustion. Therefore, the nitrogen which was used as a carrier gas was not discarded after each analysis but was used over and over again during the entire series of analyses which were made with each portion of reagent. The concentration of hydrogen or of carbon monoxide was thereby increased and could be determined somewhat more accurately than would otherwise have been possible. Even under these conditions, however, the combustion analyses were not very satisfactory. Calculations of the amounts of hydrogen based on the contraction or the amounts of oxygen consumed were not in good agreement, and the amounts of carbon monoxide calculated from the contraction, the oxygen consumed, or the carbon dioxide formed did not agree closely with each other.

This disagreement may have resulted from volumetric error (the volumes involved were small), or from the presence of small amounts of combustibles other than hydrogen or carbon monoxide. The disagreement, while apparently significant, is not serious with respect to the actual amounts of gas involved; and a selected average may be used to make approximate corrections of the analytical results.

The amount of hydrogen in the carrier gas (combined residues) from analyses 1,2 , and 3 (table 4 ), after the absorption of oxygen by neutral chromous sulfate, was determined by slow combustion. This amount when calculated from the contraction was $0.22 \mathrm{ml}$ and when calculated from the oxygen consumed was $0.32 \mathrm{ml}$. The 0.11 percent of hydrogen reported in these analyses is based on the average of these calculations. A similar examination of the carrier gas from

${ }^{10}$ The author is indebted to E. Carroll Creitz of this Bureau for this determination. 
analyses 4 to 7 , inclusive, (table 4 ) resulted in no hydrogen being found. An examination of the two portions of carrier gas from analyses 8 to 12 , inclusive, and 17 to 19 , inclusive, indicated amounts of hydrogen so small that its presence is not definitely established.

The amount of carbon monoxide in the carrier gas from analyses 18 to 25 , inclusive, table 2, was determined by slow combustion. The amount of carbon monoxide calculated to be present was $0.80 \mathrm{ml}$ from the contraction, $0.68 \mathrm{ml}$ from the oxygen consumed, and $0.60 \mathrm{ml}$ from the carbon dioxide formed. The average of these values corresponds to an 0.11 percent correction for CO.

Since this amount is approximately three times as great as the amount usually found after analyses of this type, a similar portion of this carrier gas was examined by reaction with iodine pentoxide. The correction for carbon monoxide based on this analysis is 0.07 percent; and as this method of determining small amounts of carbon monoxide is more accurate than slow combustion, this correction is reported in table 2 . It is possible that the correction calculated from the results of the slow combustion analysis indicates the presence of combustibles other than carbon monoxide in the carrier gas.

The neutral solution of chromous sulphate used in the series of analyses which resulted in the evolution of $0.27 \mathrm{ml}$ of hydrogen (average of $0.22 \mathrm{ml}$ and $0.32 \mathrm{ml}$ ) had been treated as follows before the series of analyses was made and the hydrogen evolved.

(1) $89 \mathrm{ml}$ of nitrogen was passed through the freshly prepared solution 10 times and discarded.

(2) $69 \mathrm{ml}$ of nitrogen was passed through the reagent 10 times and discarded.

(3) $62 \mathrm{ml}$ of nitrogen was passed through the reagent 4 times and discarded.

(4) $63 \mathrm{ml}$ of nitrogen was passed through the reagent 4 times and discarded.

(5) $63 \mathrm{ml}$ of nitrogen was passed through the reagent 4 times and discarded.

(6) $67 \mathrm{ml}$ of nitrogen was passed through the reagent 4 times and discarded.

(7) $62 \mathrm{ml}$ of nitrogen was passed through the reagent 4 times and discarded.

The reagent then remained idle for 3 days and was used for the analyses of oxygen here reported.

Previous experience indicates that all of the dissolved hydrogen originally in this reagent should have been swept out by the nitrogen which had been passed through it. The most probable explanation for the hydrogen which was found in the carrier gas after the oxygen analyses is that it was formed by reduction of water by bivalent chromium or else that minute pieces of zinc passed through the glass wool filter of the Jones reductor and produced hydrogen in the absorption pipette. The evolution of hydrogen sulfide from neutral solutions of chromous sulfate when the solutions had remained idle for long periods was mentioned in section III. A similar slow evolution of hydrogen may, therefore, be possible. ${ }^{11}$

${ }^{11}$ A list of references regarding the possible evolution of hydrogen from solutions of chromous sulfate is given by Stone and Beeson, footnote 3. A list of references concerning the evolution of hydrogen from solutions of chromous chloride is given by R. P. Anderson and J. Riffe, footnote 9. 


\section{DISPLACEMENT OF NITROGEN FROM CHROMOUS SOLUTIONS DURING ANALYSES}

Measurable volumes of nitrogen were found to be displaced from the chromous solutions by the passage of unabsorbed oxygen through them. These amounts were measured by making the first passage of $80-\mathrm{ml}$ samples of oxygen through the chromous solutions and then removing the oxygen which had not reacted, by repeated passages of the gas which remained through alkaline potassium pyrogallate. The differences between the volumes of nitrogen which remained after these analyses, and the volumes which remained after analyses by absorption in alkaline potassium pyrogallate alone, were assumed to be a measure of the nitrogen displaced from the chromous solutions. The amounts of nitrogen which were displaced from the chromous solutions were found to increase rapidly as the concentration of the chro-

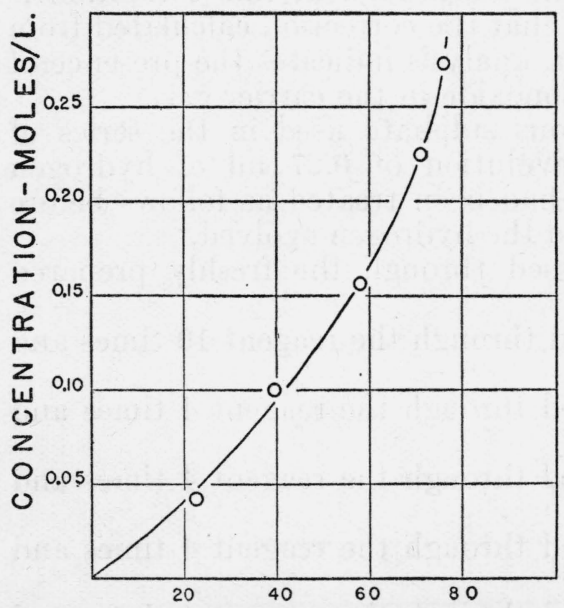

PERCENT OXYGEN ABSORBED

FIgURe 1.-Percentage of oxygen absorbed in a single passage of 80-ml samples of commercial oxygen through neutral solutions of chromous sulfate. mous solutions decreased during successive analyses. Measurements made with $260 \mathrm{ml}$ of a neutral solution of chromous sulfate showed that the amount of nitrogen which was displaced was $0.14 \mathrm{ml}$ when the solution was $0.4 M$, and $0.74 \mathrm{ml}$ when the solution was $0.1 M$. Similar measurements indicated that the amounts of nitrogen displaced from chromous chloride were seldom greater than $0.1 \mathrm{ml}$ unless the concentration of the chromous salt fell below $0.5 M$.

The measured amounts of oxygen which reacted chemically in this particular apparatus during the first passage of $80-\mathrm{ml} \mathrm{sam-}$ ples of commercial oxygen through $220 \mathrm{ml}$ of chromous sulfate are given in figure 1 . These amounts are plotted against the calculated molality of the chromous sulfate. Similar measurements made with 0.88 and $2.2 M$ solutions of chromous chloride indicated that 80 to 95 percent of the oxygen in an $80-\mathrm{ml}$ sample of commercial oxygen reacted during the first passage.

A part of the nitrogen which is displaced from the chromous solutions during the first passages of the samples through them will be redissolved during the latter part of the analyses by repeated passages of nitrogen through the reagents. The difference between the amounts redissolved in this way and those which were displaced may be large under certain conditions and constitute the principal source of error when these solutions are used in volumetric gas analysis.

Several variable conditions in the system prevent the re-solution of exactly the same amounts of nitrogen during the latter passages as 
were displaced during the first passages. The first of these variables is the change of solubility of nitrogen in the reagent caused by the rise of temperature of the reagent which occurs when oxygen reacts. This rise of temperature when $80-\mathrm{ml}$ samples of oxygen reacted under the conditions of these analyses was measured by a thermometer immersed below the surface of the reagents in the atmospheric arm of the absorption pipettes. The maximum observed temperature rises were $3.4,2.6$, and $1.4^{\circ} \mathrm{C}$ when the oxygen reacted with $220 \mathrm{ml}$ of chromous sulfate, chromous chloride, and alkaline potassium pyrogallate, respectively.

The maximum temperature rise was usually registered after the fourth passage of the sample through the reagent. Thereafter, the reagent was cooled slowly by loss of heat to the room and by the nitrogen passing through it. After the tenth passage of the sample and nitrogen through the solution of chromous chloride, the temperature of the reagent had fallen about $0.7^{\circ} \mathrm{C}$ below the maximum, so that the temperature at this time was $1.9^{\circ} \mathrm{C}$ above the initial temperature.

The changes of solubility of nitrogen with temperature in $220 \mathrm{ml}$ of $0.4 M$ chromous sulfate, $4 M$ chromous chloride (acidified) and alkaline potassium pyrogallate are reported in RP1113 to be approximately $0.025,0.01$, and $0.003 \mathrm{ml} /{ }^{\circ} \mathrm{C}$ respectively. On the basis of these temperature coefficients and the observed rise of temperature of the reagents, amounts of nitrogen which may approach $0.08,0.03$, and less than $0.01 \mathrm{ml}$ of the nitrogen displaced during the first passages of oxygen through these reagents will not be redissolved unless the reagents are brought to the temperature which prevailed before the oxygen was absorbed. This precaution was not taken when the data given in tables 1,2 , and 3 were obtained and the change of temperature of the reagents was not then measured.

Two other possible causes of error in the analytical results are: (1) That an insufficient volume of nitrogen or an insufficient number of passages of nitrogen were made during each analysis to resaturate the reagents with nitrogen; and (2) that measurable volumes of nitrogen dissolved through the open surface of the reagents in the atmospheric arm of the pipettes, after the first passages of the sample of oxygen through the reagents, at which time the reagent is relatively unsaturated with respect to nitrogen. This would prevent a like amount of nitrogen which has been displaced from the reagent from redissolving in it during the latter passages of nitrogen.

These two sources of error were studied and are reported in RP1113. This report indicates that the reagents used to absorb oxygen should have been substantially saturated $( \pm 0.02 \mathrm{ml})$ with nitrogen when six or more passages of $60 \mathrm{ml}$ of nitrogen were made during the analyses of samples of commercial oxygen. It also indicates that small but measurable amounts of nitrogen may have dissolved through the open surface of the chromous solutions in the atmospheric arm of the absorption pipette when these reagents were used to absorb commercial oxygen. 


\section{RESULTS OF ANALYSES OF MIXTURES OF OXYGEN AND NITROGEN}

The results of analyses when samples of carbon dioxide-free air and of commercial oxygen were analyzed by absorption in solutions of chromous chloride, chromous sulfate, and alkaline potassium pyrogallate are reported in this section.

The chromous solutions used in these analyses were substantially saturated ${ }^{12}$ with nitrogen and supposedly free from dissolved hydrogen prior to the start of the first analysis of each series. The open surface of the chromous solutions in the atmospheric arm of the absorption pipettes was in contact with an atmosphere of nitrogen, maintained as described in section IV. The amounts of dissolved nitrogen in these reagents at the start of the analysis following the first of a given series depended upon the amounts which had dissolved during the previous analyses, and upon the amounts which dissolved through the open surface of the reagents in the atmospheric arm of the absorption pipettes during the period between analyses.

The concentrations of the chromous solutions given in the tables are the initial concentrations at the start of each series of analyses. These concentrations were determined by pipetting aliquot parts into an excess of potassium dichromate solution and determining the excess of dichromate by titrating potentiometrically with ferrous sulfate. ${ }^{13}$

The values used to express the precision of the average results are the average of the arithmetical deviations of the separate results from the mean value of each series of analyses. The variation between the individual results is somewhat greater than would be expected from the reproducibility with which a fixed volume of gas can be measured in the apparatus.

The results of the analyses of carbon dioxide-free air are given in table 1 . The average results obtained with alkaline potassium pyrogallate and with the concentrated solutions of chromous chloride (acidified) are in good agreement with each other and with the generally accepted value of the average percentage of oxygen in air. The average results obtained with the dilute solutions of chromous chloride (acidified) and of chromous sulfate (neutral) indicate a lower apparent percentage of oxygen. These low results are attributed to the transfer of nitrogen and possibly of some hydrogen from the reagents to the gas which remained after the removal of oxygen. It is also barely possible that since the removal of oxygen can be established in this apparatus only to $\pm 0.02 \mathrm{ml}$, the low results may have been caused in part by a trace of oxygen in the residual gas. This supposition, however, is extremely improbable in view of the fact that the more concentrated solutions of chromous chloride give results which are in excellent agreement with those obtained with alkaline potassium pyrogallate.

The results of the analyses of the "air-separated" oxygen, by absorption in alkaline pyrogallate, in concentrated chromous chloride (acidified) or in $0.4 M$ chromous sulfate (neutral) are reported in tables 2, 3, and 4 .

\footnotetext{
12 The solubility of nitrogen at room temperature in 220-ml portions of chromous sulfate, chromous chloride, and alkaline potassium pyrogallate is reported in RP1113 as approximately $2.0,0.9$, and less than 0.2 ml, respectively.

13 This work was done by John L. Hague of this Bureau.
} 
TABLE 1.-Apparent percentages of oxygen in air as determined with different reagents

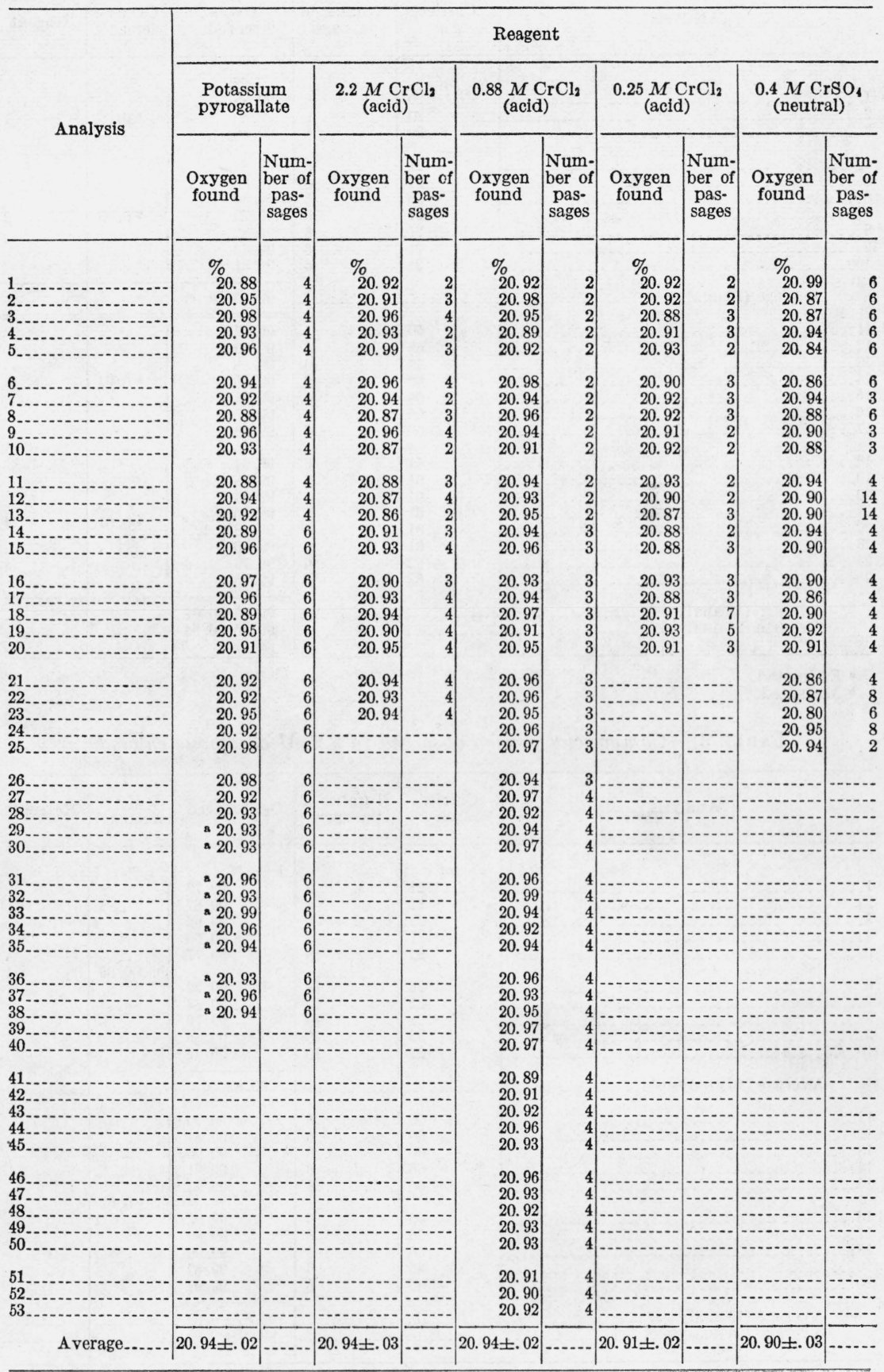

- These analyses were made by E, Carroll Creitz of this Bureau. 
TABLE 2.-Commercial oxygen absorbed in alkaline potassium pyrogallate

\begin{tabular}{|c|c|c|c|c|c|}
\hline Analysis & $\begin{array}{l}\text { Carrier } \\
\text { gas }\end{array}$ & $\begin{array}{l}\text { Number of } \\
\text { passages }\end{array}$ & $\begin{array}{l}\mathrm{O}_{2} \text { ob- } \\
\text { served }\end{array}$ & $\begin{array}{l}\mathrm{CO} \text { av- } \\
\text { erage }\end{array}$ & Reagent \\
\hline 1.20 & $\begin{array}{ll}m l & \\
20 \\
20 \\
20\end{array}$ & $\begin{array}{l}6 \\
6 \\
6\end{array}$ & $\begin{array}{l}9 \% \\
99.88^{\circ} \\
99.86 \\
99.86\end{array}$ & $\left\{\begin{array}{l}\% \\
=0.03\end{array}\right.$ & 1 \\
\hline 6 & $\begin{array}{l}21 \\
21 \\
30 \\
21 \\
21 \\
21 \\
21\end{array}$ & $\begin{array}{l}6 \\
6 \\
6 \\
6 \\
6 \\
6 \\
6\end{array}$ & $\begin{array}{l}99.89 \\
99.85 \\
99.80 \\
99.79 \\
99.82 \\
99.89 \\
99.81\end{array}$ & b 0.03 & 2 \\
\hline Average (10 analyses) & &.- & $99.85 \pm 0.03$ & - n & (n........... \\
\hline $1{ }^{12}$ & $\begin{array}{l}59 \\
68 \\
66 \\
66 \\
66 \\
66 \\
66\end{array}$ & $\begin{array}{l}6 \\
6 \\
6 \\
6 \\
6 \\
6 \\
6\end{array}$ & $\begin{array}{l}99.93 \\
99.89 \\
99.88 \\
99.76 \\
99.91 \\
99.85 \\
99.88\end{array}$ & s 0.03 & 3 \\
\hline 18 & $\begin{array}{l}61 \\
61 \\
61 \\
61 \\
61 \\
61 \\
62 \\
62\end{array}$ & $\begin{array}{l}6 \\
8 \\
8 \\
6 \\
6 \\
6 \\
6 \\
6\end{array}$ & $\begin{array}{l}99.84 \\
99.88 \\
99.84 \\
99.85 \\
99.78 \\
99.86 \\
99.79 \\
99.75\end{array}$ & b 0.07 & 4 \\
\hline $\begin{array}{l}\text { Average (15 analyses) } \\
\text { Average (25 analyses) }\end{array}$ & (n) & 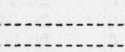 & $\begin{array}{l}99.85 \pm 0.04 \\
99.85 \pm 0.04\end{array}$ & - & (-) \\
\hline
\end{tabular}

- Estimated.

- Measured.

TABLE 3.-Commercial oxygen absorbed in $2.2 M$ chromous chloride

\begin{tabular}{|c|c|c|c|c|c|}
\hline Analysis & $\begin{array}{l}\text { Carrier } \\
\text { gas }\end{array}$ & $\begin{array}{c}\text { Number of } \\
\text { passages }\end{array}$ & $\mathrm{O}_{2}$ observed & $\underset{\text { average }}{\mathrm{H}_{2}}$ & Reagent \\
\hline 5 & $\begin{array}{ll}m l & \\
21 \\
22 \\
22 \\
21 \\
22\end{array}$ & $\begin{array}{l}3 \\
4 \\
5 \\
5 \\
8\end{array}$ & $\begin{array}{r}\%_{99.79} \\
99.87 \\
99.82 \\
99.69 \\
99.77\end{array}$ & $\begin{array}{l}\% \\
\% 0.05\end{array}$ & \\
\hline $9^{6}$ & $\begin{array}{l}22 \\
22 \\
22 \\
22 \\
22\end{array}$ & $\begin{array}{l}13 \\
10 \\
10 \\
10 \\
10\end{array}$ & $\begin{array}{l}99.92 \\
99.83 \\
99.79 \\
99.89 \\
99.82 \\
\end{array}$ & & \\
\hline A verage (10 analyses) & & & $99.82 \pm 0.05$ & & \\
\hline 113 & $\begin{array}{l}66 \\
66 \\
66 \\
66 \\
66\end{array}$ & $\begin{array}{l}6 \\
6 \\
6 \\
6 \\
6 \\
6\end{array}$ & $\begin{array}{l}99.90 \\
99.81 \\
99.90 \\
99.81 \\
99.93\end{array}$ & & \\
\hline 18 & $\begin{array}{l}66 \\
66 \\
66 \\
66 \\
66\end{array}$ & $\begin{array}{l}6 \\
6 \\
6 \\
6 \\
6 \\
6\end{array}$ & $\begin{array}{l}99.92 \\
99.80 \\
99.90 \\
99.82 \\
99.91\end{array}$ & -0.02 & \\
\hline $\begin{array}{l}\text { Average (10 analyses) } \\
\text { Average (20 analyses) }\end{array}$ & ......... & $\ldots$ & $\begin{array}{l}99.87 \pm 0.05 \\
99.85 \pm 0.05\end{array}$ & ... & \\
\hline
\end{tabular}

s Measured. 
TABLE 4.-Commercial oxygen absorbed in $0.4 M$ chromous sulphate

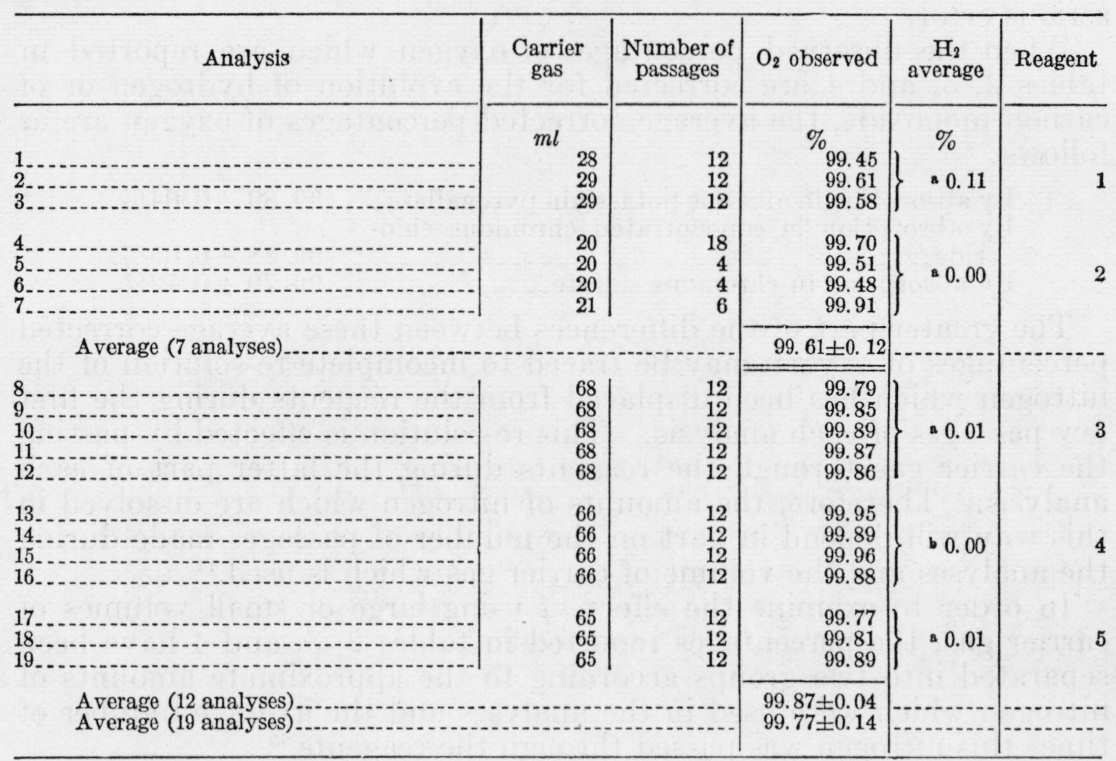

a Measured.

b Estimated.

These results are arranged with reference to the analyses from each portion of a given reagent, the amounts of nitrogen used as a carrier gas and the number of passages of the samples through each reagent. Since the carrier gas was stored above the reagent at the beginning of each analysis, it made one less passage through the reagent than did the sample. The volume of the sample of oxygen was approximately $80 \mathrm{ml}$ for each of the analyses.

The principal sources of systematic errors in the average observed percentages of oxygen reported in tables 2, 3, and 4 are:

1. The evolution of hydrogen from the chromous solutions or of carbon monoxide from the alkaline potassium pyrogallate. (The presence of either of these gases in the gas which remained after the absorption of oxygen would be measured as nitrogen from the sample and cause the apparent percentage of oxygen to be low.)

2. The transfer of nitrogen between the reagents and the samples of gas being analyzed.

The errors from the first of these two sources were measured for 8 of the 11 portions of reagents used to obtain the data given in tables 2,3 , and 4 . These measured percentage errors are given in columns 5 of these tables.

The carrier gas from analyses 1 to 3 , inclusive, and 11 to 17 , inclusive, of table 2 was not examined for carbon monoxide. The percentages $(0.03 \%)$ marked "estimated" in column 5 of this table are based on previous experience with this combination of reagent, gas sample, and absorption pipette.

The carrier gas from analyses 13 to 16 , inclusive, of table 4 was not analyzed. Because of the high average percentage of oxygen observed in these analyses, it has been assumed that the amounts of 
hydrogen evolved were sufficiently small to be neglected without serious error.

When the observed percentages of oxygen which are reported in tables 2, 3, and 4 are corrected for the evolution of hydrogen or of carbon monoxide, the average corrected percentages of oxygen are as follows:

By absorption in alkaline potassium pyrogallate.

By absorption in concentrated chromous chloride

99. $89 \pm 0.04 \%$.

By absorption in chromous sulfate

99. $88 \pm 0.05 \%$.

99. $79 \pm 0.12 \%$.

The greater part of the differences between these average corrected percentages of oxygen may be traced to incomplete re-solution of the nitrogen which has been displaced from the reagents during the first few passages of each analysis. This re-solution is effected by passing the carrier gas through the reagents during the latter part of each analysis. Therefore, the amounts of nitrogen which are dissolved in this way will depend in part on the number of passages made during the analyses and the volume of carrier gas which is used. ${ }^{14}$

In order to examine the effect $r f$ using large or small volumes of carrier gas, the percentages reported in tables 2,3 , and 4 have been separated into two groups according to the approximate amounts of nitrogen which were used in the analyses and the average number of times this nitrogen was passed through the reagents. ${ }^{15}$

The average corrected percentages of oxygen observed when approximately $20 \mathrm{ml}$ of carrier gas was used are as follows:

1. By alkaline potassium pyrogallate, 6 passages_- $99.88 \pm 0.03 \%$.

2. By chromous chloride, concentrated, 6 passages_ $99.87 \pm 0.05 \%$.

3. By chromous sulfate, dilute, 10 passages . . . . $99.65 \pm 0.12 \%$.

The average corrected percentages of oxygen observed when approximately $60 \mathrm{ml}$ of carrier gas was used are as follows:

4. By alkaline potassium pyrogallate, 6 passages_- $99.90 \pm 0.04 \%$.

5. By chromous chloride, concentrated, 6 passages_ $99.89 \pm 0.05 \%$.

6. By chromous sulfate, dilute, 12 passages ...... 99. $87 \pm 0.04 \%$.

7. By chromous chloride, concentrated, 12 passages 16

8. By alkaline potassium pyrogallate, 12 passages ${ }^{16}$

99. $91 \pm 0.05 \%$.

99. $92 \pm 0.04 \%$.

The errors shown by the large differences between the average corrected percentages of oxygen reported in 1, 2, and 3 become smaller when the amounts of carrier gas are increased from 20 to $60 \mathrm{ml}$. Therefore, if the analyst is not concerned with errors which are less than approximately 0.05 percent, the discussion of these first three series of analyses may be limited to a simple warning that large volumes of carriergas should be passed repeatedly through solutions of chromous sulfate when this reagent is used to determine oxygen volumetrically.

If, however, the analyst is concerned with errors of approximately 0.01 or 0.02 percent, the differences between the average corrected percentages reported in $4,5,6,7$, and 8 are significant.

14 The amounts of "carrier" or "push" gas used in volumetric gas analysis vary considerably. Many analysts use none whatever, and amounts of less than $20 \mathrm{ml}$ are used more frequently than larger volumes.

${ }_{13}$ It should be noted that any oxygen which does not react during the earlier analyses of a series will remain in the carrier gas and have the opportunity to react during the analyses which follow. Therefore, only that oxygen, if any, which does not react in the last analysis of a series will affect the average percentage of oxygen calculated from the series of analyses. The possibility of incomplete absorption of oxygen measurably affecting the average results of a series of analyses is, therefore, extremely remote.

${ }_{16}$ These data are not given in tables 2 and 3 . They were obtained by making additional passages of nitrogen in analyses 11 to 20 , inclusive, of table 3 and 18 to 25 , inclusive, of table 2. 
The discussion of the possible sources of error which are indicated by the differences between these average corrected percentages is made difficult by the fact that the actual percentage of oxygen in the samples which were analyzed is not known. Furthermore, since the errors from all sources are measured simultaneously it is not possible to arrive at a definite conclusion regarding the magnitude of the error from a single source.

One source of probable error in these results is the change of solubility of nitrogen in the reagents with the changes of temperature which are caused by the heat liberated when oxygen reacts with them. The changes of solubility of nitrogen in $220 \mathrm{ml}$ of chromous sulfate, chromous chloride, and alkaline pyrogallate are reported in section VII as $0.025,0.01$, and $0.003 \mathrm{ml} /{ }^{\circ} \mathrm{C}$, respectively.

The effect of change of temperature during a series of analyses depends on the temperature of the reagent at the start of the first analysis and at the end of the last analysis of the series.

The changes of temperature which occurred during many of the analyses reported in tables 2,3 , and 4 were not recorded. The increase of temperature, after 12 passages of carrier gas, during analyses 11 to 20 , inclusive, of table 3 was $4.1^{\circ} \mathrm{C}$, or approximately $0.4^{\circ} \mathrm{C}$ for each analysis, while the increase during analyses 17 to 19 , inclusive, of table 4 was $2.2^{\circ} \mathrm{C}$, or $0.7^{\circ}$ for each analysis. ${ }^{17}$

These changes of temperature, together with the temperature solubility coefficients of nitrogen given above, correspond to a correction of about 0.02 percent in the average percentage of oxygen as determined by absorption in chromous sulfate and about 0.01 percent when the absorption was made by 12 passages through chromous chloride. The corresponding estimated change in the average percentage of oxygen as determined by 12 passages through alkaline potassium pyrogallate is negligibly small.

When the percentages given in 6,7 , and 8 of page 58 are corrected for changes of solubility of nitrogen in the reagents with temperature they become:

9. By chromous sulfate

10. By chromous chloride, concentrated ..... $99.92 \pm 0.05 \%$.

11. By alkaline potassium pyrogallate $\ldots . . . . . . .99 .92 \pm 0.04 \%$.

Two additional possible sources of error in these corrected results will be discussed briefly. The first of these is the possibility that the reagents were not saturated with nitrogen at the final temperature of the reagents when $60 \mathrm{ml}$ of nitrogen was passed through them 12 times during each analysis.

On the basis of the data reported in RP1113, it appears that these reagents were substantially saturated with nitrogen $( \pm 0.02 \mathrm{ml})$ after six passages of $60-\mathrm{ml}$ portions of carrier gas had been made. Therefore, it is concluded that no measurable error caused by failure to saturate the reagents with nitrogen is involved when the sample and $60 \mathrm{ml}$ of carrier gas were passed 12 times through the reagents.

A second possible source of error in these corrected results is indicated by the measurements reported in RP1113. This paper shows that measurable volumes of nitrogen may pass through the open surface of these reagents in the atmospheric arm of the absorption

17 When a series of analyses is made in rapid succession, the temperature gradient which develops between the reagents and the air of the laboratory cools the reagents much more rapidly than when only a single analysis is made. 
pipettes and that a layer of liquid petrolatum over the alkaline potassium pyrogallate will not prevent this passage. The direction and rate of this passage of nitrogen depend on the fractional saturation of the surface of the reagents with nitrogen as compared to the partial pressure of nitrogen in the gas above the open surface of the reagent. The rate of passage is also proportional to the solubility of nitrogen in the reagent.

On the basis of the amounts of dissolved nitrogen which are displaced from the solutions of chromous sulfate and chromous chloride during the absorption of oxygen (see section VII), and the solubility of nitrogen in chromous sulfate, chromous chloride, and alkaline potassium pyrogallate (see RP1113), much more nitrogen may dissolve through the open surface of chromous sulfate than of chromous chloride, while very small amounts of dissolved nitrogen may pass from the potassium pyrogallate into the air above the oil on its open surface. In addition to the loss of dissolved nitrogen from potassium pyrogallate, very small bubbles of this gas have been observed to pass from the distributor tip and through the open surface in the atmospheric arm of the absorption pipette during analyses. This occurs when the rate of passage of gas into the pipette from the burette is so rapid that the very small bubbles are carried downward with the displaced liquid into the atmospheric arm of the pipette. The amounts of nitrogen lost from the burette in this way may be as much as $0.001 \mathrm{ml}$ per passage. A similar loss of gaseous nitrogen through the chromous solutions is thought not to have occurred.

It is not possible to estimate the effect of the passage of nitrogen through the open surface of the reagent on the percentages reported in 9,10 , and 11 . It is quite possible, however, that the passage of dissolved nitrogen may have been responsible for the greater part of the difference between these final percentages.

\section{CONCLUSION}

The agreement which may be obtained between the average corrected percentages of oxygen as determined by absorption in these reagents is of interest. From a practical standpoint, however, the analyst is concerned with observed rather than with corrected results. On this basis, alkaline potassium pyrogallate or concentrated solutions of chromous chloride are to be preferred to dilute solutions of chromous sulfate when mixtures of oxygen and nitrogen are to be analyzed.

Many other secondary factors should be considered when the choice of an oxygen absorbent is to be made. Some of these will be discussed briefly.

Alkaline potassium pyrogallate may be prepared somewhat more rapidly than either of the chromous solutions, provided a stock solution of the proper concentration of potassium hydroxide is available. On the other hand, if the need of concentrated chromous chloride is anticipated it may be prepared and kept over amalgamated zinc in a loosely stoppered flask. This reagent must, however, be saturated with nitrogen and freed from dissolved hydrogen before being used.

The volume of oxygen which may be completely absorbed by alkaline potassium pyrogallate has been reported ${ }^{18}$ as about 27 times the volume of the reagent when the absorption is made by shaking the

${ }^{18}$ See footnote 7 , page 49. 
sample in a Hempel pipette over mercury. This capacity, however, was not realized in the analyses reported in this paper because the small perforations in the distributor tips of the absorption pipettes became clogged with a precipitate after the volume of absorbed oxygen approached three time the volume of reagent. The volume of oxygen which may be absorbed in chromous chloride will vary with the concentration of the solution. One volume of a $2 M$ solution of chromous chloride will absorb about eight volumes of oxygen before the concentration of bivalent chromium decreases to $0.5 \mathrm{M}$. The time required to absorb the oxygen from a given sample and to redissolve most of the nitrogen which has been displaced from the reagent is less when either potassium pyrogallate or concentrated chromous chloride is used than with dilute chromous sulfate.

The passage of the samples through the chromous solutions does not give rise to foaming. When alkaline potassium pyrogallate is used, foaming may occur and cause delay before the gas can be returned to the burette for measurement.

The passage of very small bubbles of gas from the sample and the loss of these bubbles in the atmospheric arm of the absorption pipette, which occurs when the samples are passed rapidly through alkaline potassium pyrogallate, do not occur when the chromous solutions are used in the same type of absorption pipette.

The chromous solutions do not etch stopcocks rapidly, if at all.

When the samples to be analyzed contain gases other than oxygen and nitrogen, the solution and displacement of each of the "inert" constituents of the samples in the oxygen-absorbent must be considered carefully. Nitrogen is less soluble in alkaline potassium pyrogallate than in either of the chromous solutions, but little is known concerning the solubility of other inert gases in these reagents. Therefore, until data concerning these solubilities are available it is unwise to change from a reagent which has been used over long periods to one with which the analyst is unfamiliar.

Washington, April 4, 1938. 